\title{
Ciberespacio, signos y comunicación
}

\author{
ANTULIO SÁNCHEZ \\ Director de la revista Topodrilo de la UAM Iztapalapa, \\ División de Ciencias Sociales y Humanidades \\ E-mail:asga@ xanum.uam.mx
}

\begin{abstract}
RESUMEN
En este trabajo se analizan las nuevas formas de interacción y transmisión del conocimiento, que se dan en el interior de los mundos virtuales inmersos en el ciberespacio. Se detalla sobre la idea de comunicación interactiva y la cultura sígnica que se gesta, a partir del uso de la tecnología de cómputo y telecomunicación.
\end{abstract}

\begin{abstract}
This paper analyzes the new forms of knowledge interaction and transmission which are given within the virtual worlds of cyberspace. The idea of interactive communication and sign culture, stemming from the use of computer technology and telecommunication, is detailed.
\end{abstract}

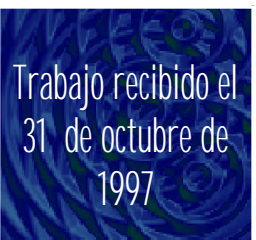

Con la llegada del ciberespacio, se ensancha el mundo virtual. El mundo virtual que nos interesa describir aquí es el electrónico, los "lugares" donde se simulan experiencias de tipo multimedia, bimediales o incluso unimediales. Los mundos virtuales no son sólo puentes o mediaciones para entender la realidad, sino que constituyen una de las formas más perfeccionadas en que se genera la cultura del próximo siglo. Los mundos virtuales ${ }^{1}$ según se menciona a partir de distintos medios de comunicación, se tornan en la nueva forma de aprehender la realidad, de relacionarnos con el otro, de vivir la experiencia existencial de

1 Es cierto que en todos los trabajos que se remontan a la filosofía, la sociológica, psicología, teoría literaria e incluso la sociología, prevalece la línea de estudio de lo virtual como una cuestión que va siempre de lo virtual hacia lo real. Sin embargo, el francés Pierre Lévy en su estupendo texto Qúest-equelevirtud? (la découverte, París, 1995), traza el camino inverso: dibujar cómo desde lo real se ha construido un sinfín de vías o de ambientes totalmente virtuales. Para él, los mejores vehículos de virtualización son precisamente los artefactos de $\mathrm{G}$ utenberg y un sinnúmero de mecanismos civilizadores que la humanidad ha puesto en marcha. Sobre lo que constituyen estos mundos virtuales, me he extendido en otra parte. Cfr. Antulio Sánchez. Teritariosvirtuales DeInternet haia un nuevoconceptodela simlación Taurus, México, 1997. 
fin de siglo, de transmitir el conocimiento. Los mundos virtuales son la conformación de un espacio artificial, simbólico, posible gracias al ciberespacio y permiten a los individuos poner en marcha aspectos económicos, políticos, amistosos, lúdicos, etcétera; las proyecciones y figuraciones simbólicas, que circulan por el ciberespacio, son capaces de dar un significado destacado a la existencia de los individuos.

Pero antes de continuar de lleno con esta línea de los mundos virtuales electrónicos, debo mencionar que desde que el humano es tal, siempre ha tenido que recurrir a la mediación virtual para relacionarse y comprender su entorno. La magia, los múltiples caminos de la estética o la misma ciencia y técnica son tanto procesos de virtualización como medios por los cuales los individuos podemos lograr este paulatino, pero imparable, proceso de virtualización. Por el libro, imaginamos y trazamos escenarios, damos coherencia y proponemos la clarificación del entorno; o lo que es lo mismo, por medio de la virtualización del vector libro construimos y reconstruimos el mundo con aspectos que nos son significativos, de esta manera nutrimos nuestro imaginario individual y colectivo. Así pues, los mundos virtuales naturales y artificiales son resultado lógico del largo proceso de hominización. Las diferencias entre ambos son evidentes: el mundo virtual natural se caracteriza por ser un conjunto de imágenes no del todo interactivas, que provienen de la fantasía y la imaginación, pero que tienen la factibilidad de ser vividos y explorados, el efecto que genera en quienes se acercan a él se puede dar en el mismo momento en que se "entra en contacto" o de manera retardada; los dos se caracterizan por producir una relación de corte subjetivo.

Por su parte, un mundovirtual sintéticooartifical es el que corre o se hace posible en el ciberespacio, está conformado por una base de datos gráfica e interactiva, es un programa explorable en tiempo real o no bajo forma de imágenes de síntesis tridimensionales; una parte del mismo es inmersivo y permite generar el sentimiento de adentramiento en la figura 0 ambiente simulado, aunque la cuestión subjetiva es lo característico. Esta segunda modalidad de los mundos virtuales, no es necesariamente inmersiva e incluso ya era explotada de manera evidente por el cine, la televisión, el video, etcétera.

A partir de este momento, para no entrar en confusión, designaré con el término de ciberespacio todo lo que anteriormente refería con el de mundo virtual artificial. De esta manera, el ciberespacio no sólo es la infinita zona atópica que está detrás del monitor, sino que es el terreno en donde se construye y genera conocimiento, 0 donde se cambia de identidad o vive de manera distinta el acto comunicativo, donde las perspectivas y los enfoques singulares se desenvuelven.

Lo que se destaca en esta definición de ciberespacio, e incluso va en contra de la opinión mayoritaria, es la relación que establece el usuario con tales medios, la cual se caracteriza por ser subjetiva, ${ }^{2}$ cuestión que a lo largo de las siguientes páginas intentaré dejar aclarado. Para lograr esto, me serviré de 
algunas ideas sostenidas por uno de los grandes inventores e investigadores del ciberespacio, quien ha sostenido la posibilidad de arribar, gracias precisamente a estas tecnologías, a una comunicación transparente, libre de distorsión o confusión interpretativa y ausente de mediaciones sígnicas.

Antes de avanzar, me gustaría abrir un paréntesis para reflexionar un poco más sobre lo que constituye la cuestión ciberespacial. Buena cantidad de textos abunda, y con buena fortuna, en lo que conforma al ciberespacio, su génesis y su uso.

D entro de las varias tendencias destacan las que lo ubican como manifestación expresa de lo inmaterial o bien como una especie de espejo de la realidad. ${ }^{3}$ Si bien la primera de estas ideas me parece que no posee consistencia, en el caso de la segunda creo necesario abundar al respecto. Reflejada la realidad, sin duda, está en Internet, y esto es algo que me parece no está sujeto a descrédito porque de todos es sabido que cuando nos comunicamos con otras personas a través del correo electrónico, la máquina se torna en una mediadora, pero somos nosotros los que decidimos de manera directa 0 indirecta (por medio de una secretaria 0 algún ayudante), poner en marcha el proceso de comunicación. A pesar de que en el futuro se cuenten con motores de búsqueda, robots más perfeccionados que Marimba, por ejemplo, estos dispositivos "inteligentes" que se agrupan bajo el marbete de tecnología Push seguirán siendo instancias programadas por los usuarios para llevar a cabo distintas tareas de mediación. Por esto mismo no le quitará al ciberespacio su doble faceta: ser real en tanto que son usuarios de carne y hueso quienes lo usan para cuestiones distintas; pero al mismo tiempo virtual en cuanto todo corre dentro de la pantalla, en el interior de un no lugar, una región atópica. 4

Expresado lo anterior, quisiera avanzar hacia la idea de la comunicación interactiva y la cultura sígnica en la que, por cierto, sólo un sector minoritario de este país se ha adentrado. El místico Mircea Eliade decía que "únicamente los músi-

2 El francés Pierre Lévy ha trabajado sobre esta línea. A unque no lo hace de manera explíita, él marca la cualidad de estos instrumentos como subjetivos. Véase al respecto, su texto L'ideogaphiedyna mique (la découverte, París, 1991).

3 No comparto esto de la inmaterialidad, porque tal parece que toda cuestión que circula por los diferentes vectores o soportes tecnológicos fuera una cuestión ausente no sólo de medición y cuantificación, sino que borra con pragmática y dogmática visión cualquier procedencia subjetiva de un ente concreto en el acto creativo. Una aclaración pertinente sobre este equívoco se encuentra en Tomás Maldonado. Real yvirtual, G edisa, Barcelona, 1994.

4 Es evidente que esto es posible gracias a la mediación clónica, a la representación que permite el mecanismo de bits o binario de la red. Se me puede objetar que en el caso de la realidad virtual, por ejemplo en las librerías virtuales, a veces, lo que se representa no existe en la realidad. En primer lugar, debe destacarse que en muchos casos lo simulado en este nivel está inspirado en obras literarias, políticas, pictóricas...pero, incluso, a pesar de que no lo fueran, no puede soslayarse que ellas derivan de un proceso de subjetivación, de un específico acto cognitivo. Además, no pasemos por alto que todo lo que hay en un disco duro o en un CD-ROM es cuantificable, es algo que puede ser reducido a electrones y, por ende, a materia. 
cos, los chamanes o los soberanos logran establecer, de una manera pasajera y sólo por su propia práctica, la comunicación con el cielo." 5 Sin embargo, se dice que gracias a la interactividad, esta cuestión ya está al alcance de un mayor y significativo grupo de seres humanos.

\section{Interactividad y signos}

Gracias a la interactividad es como se da paso a una buena explotación del ciberespacio ${ }^{6}$ sea en su modalidad internetiana o en un CD-ROM. Sólo con la interactividad es como la navegación o la exploración del ciberespacio adquiere sentido. D e esta manera, las imágenes y las informaciones que circulan en el ciberespacio pueden ser seleccionadas, contempladas, ligadas, modificadas 0 reconstruidas.

La interactividad no es una cuestión nueva, pero en lo referente a los medios de comunicación sí se presenta como un producto reciente y, sobre todo, demandado ya desde fines de los sesenta por algunos sectores como algo necesario. D ebe recordarse que una fracción del movimiento estudiantil estadunidense de fines de los sesenta, el que se ramificó en la utopía contracultural con medios electrónicos, denunciaba con fuertes calificativos la tiranía y la antidemocracia ejercida por la comunicación de masas, exigía una comunicación bidireccional, horizontal, en donde el papel pasivo del consumidor de información se modificara. D e esta manera, la interactividad era el eslabón que conducía a la democracia. Hoy no cabe duda de que la práctica interactiva se presenta de manera evidente en el ciberespacio, es su medio idóneo, ${ }^{7}$ aunque tampoco sirve para llegar al cielo.

Interacción, nos dice el Diciananodela Røal Acadania, es una cuestión que designa la "acción que se ejerce de manera recíproca entre dos o más objetos, agentes, fuerzas, funciones, etcétera." ${ }^{8}$ Sin embargo, la palabra se asocia cada vez más con los soportes electrónicos e incluso ha contaminado a los otros medios que sin reparo alguno se autodesignan de interactivos. Véase como erróneamente la radio, la misma televisión acuden al recurso de que todo lo que hacen es interactivo, o incluso la publicidad ya nos ofrece refrescos interactivos o fast foolcon grados de

5 Mircea Eliade. Imágensy yśmbdos, ensayos sdbred simbdismomágicordigioso Taurus, Madrid, 1979.

6 El ciberespacio, tal como lo defino, significa que ya estaba en el teléfono, el telégrafo, el cine, pero después continuó, de manera masiva, extendiéndose a través de varias artes visuales, hasta llegar a una modalidad interactiva soportada por bits.

7 Estoy de acuerdo con que la verdadera comunicación es aquella que se da cuando se presenta una transmisión en doble sentido, es decir, se avanza hacia cierta zona y se retorna de ella con algo; cuando las partes que intervienen entran en el intercambio de bienes, sean éstos los que sean. Por eso, el instrumento más horizontal y virtual que usamos con mayor frecuencia es el teléfono 0 nuestra misma corporeidad como tal.

Cfr. Françoise Holtz-Bonneau. L'imageđl'ardinatar, Aubier, París, 1986.

8 Dicionarioilustradbdela lengra españda, Barcelona, 1980. 
interactividad, a través de máquinas tragamonedas. Con la palabra interactivo se trata de designar o calificar a ciertos componentes, los soportes materiales y lógicos y sus condiciones de explotación, es decir, las características de acceso y el tipo de relación que se establece con dichos paquetes. En este sentido, lo interactivo vendría a ser una manera de calificar a los materiales, los programas y las condiciones de acceso al software; es la manera en que se dan los "intercambios" informativos entre la computadora y el usuario, y le permiten a este último orientar el desarrollo de las operaciones. No me interesa abundar tanto en los niveles y grados de interactividad, sino señalar que el más perfeccionado sería el que posibilita no nada más recibir información, sino el que modifica el bien informativo, el que permite a los individuos que "surfean por las costas del ciberespacio" no sólo recibir información sino remitir, también, información. A partir de esta cualidad de los soportes, se piensa por Lanier y compañía que estamos ante el advenimiento de un lenguaje carente de signos, del verdadero esperanto que hará posible la llegada de la comunicación objetiva, de la mística convertida en práctica cotidiana. Esta radical transparencia en la comunicación, es el equivalente a alcanzar el cielo. Es decir, que la virtualidad será el elemento más idóneo para lograr el diálogo diáfano entre los seres humanos, el pivote de un auténtico diálogo transparente, consensuado y ausente de ruidos. La buena interactividad será la que dará paso al advenimiento de una comunicación sin distorsión o sin filtros interpretativos, en la cual ya no estará o no tendrán razón de ser los criterios de interpretación. ${ }^{9}$ Llevada a su extremo, pero con cierto matiz caricaturesco, esta idea diría que el mismo especialista ya no tendrá problema alguno para ser comprendido; las disputas que puedan darse en el caso de corrientes, escuelas o teorías serán resueltas al ser comprendidas por todos y hasta es pensable una uniformidad consensuada del pensamiento. Esto, al menos como idea, no deja de ser seductor para muchos, sobre todo cuando la academia se ramifica en trincheras y están a la orden del día la multiplicidad de líneas y enfoques para tratar una problemática.

Recordemos que son los grandes artífices de estos nuevos medios de comunicación, quienes han sostenido esta idea de prescindir de los signos para lograr un mejor entendimiento entre los seres humanos y para conocer la realidad. D esde algunas personalidades importantes de empresas como Cisco, el mismo Steve Jobs, uno de los dos pesonajes sensación que construyeron la Apple, o Jaron Lanier (confeccionador de uno de los guantes de datos), entre otros, se han encargado de difundir a los cuatro vientos que una nueva generación de soportes materiales y lógicos hará posible la verdadera comunicación y concretar este

9 Suficientes experiencias tenemos para decir que la interactividad no es la panacea para resolver todo. No es superfluo decir que la interactividad en el campo de la televisión ha evidenciado que ese medio ha carecido de un trasfondo cultural. Usada tal como se viene haciendo, en la mayoría de los casos, de nada sirve, sólo viene a incrementar el caudal de superficialidad en que se ha regodeado la oferta televisiva. 
anunciado ambiente celestial. ¿Pero qué entienden estos atletas de las nuevas tecnologías por una real comunicación? No se puede saber, cuando poco explícitos son estos personajes para ilustrar su idea, pero al menos, siguiendo a Lanier, que ha sido más abierto, sí se puede tener una idea.

Para él, el lenguaje empezará cada vez más a perder buena parte de sus funciones y su misma importancia cultural, ya no signará una determinada pertenencia geográfica y cultural. Para él, los actuales medios convencionales de comunicación electrónica, pero sobre todo el lenguaje, constituyen una limitación para poder hacer accesible y poner al alcance de los seres humanos lo que piensan y sienten. Todo lenguaje es, según la idea de Lanier, un dispositivo exclusivo de comunicación, es más: la lengua surge ahí donde la limitación física y tecnológica impide que se transmita fielmente lo que uno percibe, el lenguaje no logra que lo pensado o sentido por una persona sea comprendido de igual manera por el receptor del mensaje. Para él, en el largo y perenne desarrollo de la humanidad, el lenguaje ha tenido la labor de hacer menos pesada las mismas "limitaciones" físicas, las restricciones del ambiente y es resultado de la imposibilidad de no contar con un medio más eficaz para comunicarse o representar el mundo. Lanier dice que tal como está estructurado hoy día el mundo de la comunicación, la experiencia es incomunicable. Para él, "el lenguaje está limitado, uno no puede servirse de él para actuar en directo sobre la realidad [...] Es un flujo de pequeños símbolos discretos, pero el mundo está constituido de movimientos y continuidades. El lenguaje no puede sugerir ni reproducir la realidad ni crearla. Ninguna pintura podrá ser del todo descrita por palabras, mucho menos el mundo." ${ }^{10} \mathrm{De}$ esta manera, Lanier ve el lenguaje como un acompañante imperfecto para dar cuenta de las cosas; por más profunda y "transparente" que sea la palabra, no alcanza la esencia de las cosas; se queda en la superficie y a lo más que llega es a acariciar una limitada parte de lo que se desea describir. Es la dureza y diversidad de factores ambientales que el mismo hombre construye, los que lo obligan a recurrir al lenguaje.

Un verdadero instrumento de comunicación no sólo es el que transmite fielmente a los otros nuestros pensamientos e ideas, sino que para lograr nuestro objetivo comunicacional debe facilitarnos modificar también nuestra configuración biológica. Por eso, el mejor medio comunicativo es el que se da en el ciberespacio, el que permite alterar contextos, es el único capaz de controlar la totalidad del mundo sensible del receptor del mensaje. Se piensa que cada vez nos acercamos más a esto a partir de la realidad virtual, incluso recuérdese que para la misma red Internet se está pensando en crear moléculas artificiales 0 virtuales, para que los olores viajen por la red de redes. Para Lanier, a medida que se perfeccionen los programas y los sistemas inmersivos se incrementen, el lenguaje perderá sentido e incluso, y esto sin decirlo en forma directa, desaparecerá.

10 Entrevista aJaron Lanier en Whdeertreview USA, O toño de 1989. Tomado de Pierre Lévy, Op Cit. 
Comparto con Lanier que toda lengua al ponerse en marcha tiene como fin mantener, modificar o incluso destruir lo que refiere. Ésa es, precisamente, una de las varias cuestiones que lo hacen rico e incomparable. Es cierto que quien comunica, intenta que quienes reciben el mensaje lo capten de acuerdo a como él lo siente o desea que lo sientan, pero como maniobra sensorial, sensibiliza e incluso puede llevar a alterar la conducta. El lenguaje, la entonación, el contexto, la herencia genética, la cultura, la indiosincrasia...son algunos ingredientes que hacen del lenguaje un vehículo no homogéneo en la transmisión de mensajes a distintas personas. La palabra, la lengua, es antes que nada, acción, estimula y modifica, pero ambos aspectos también son históricos y cambian conforme los humores de las personas y el momento histórico en que se designan 0 usan. ${ }^{11}$

Equivocado está Lanier cuando piensa que el ciberespacio generará un cambio radical de tal situación, que hará del lenguaje algo transparente y marcará la llegada de la intersubjetividad que desea darle a la virtualidad. La virtualidad expresada por las bases de datos o cualquier modalidad de bits, no sólo tiene por función alterar lo que simula, sino que genera pautas interpretativas. El ciberespacio sólo es factible gracias a las computadoras, a una interfase administradora de signos; la operación de tales máquinas se debe a la puesta en marcha de procesos o lenguajes formales, es decir, de operaciones simbólicas. Cualquier programa o soporte lógico que activemos o que nos permita desencadenar alguna operación, pone en función estructuras sígnicas. Toda comunicación tiene que recurrir a ella, no hay comunicación sin signos.

Toda la parafernalia y retórica que se pone en operación para lograr la comunicación virtual o mediada por computadoras, se transforma en signos, es así como llega al usuario. "A pesar de que las 'experiencias' sensoriomotoras de los mundos virtuales se transmiten de manera directa, no es posible comunicar sin intermediación sígnica, ni traducir las prácticas reales del mundo 'verdadero' sin los signos". ${ }^{12}$ Cualquier transmisión de pensamiento, de ideas, se traduce de manera obligatoria en signos. Coincido, parcialmente, en que, tal vez, el mejor administrador de signos hoy día sea el ciberespacio usado en modalidad de realidad virtual, porque gracias a su cualidad de facilitar operaciones en tiempo real y de manipular los signos de manera "directa" con "nuestras manos", permite hacer modificaciones inmediatas del objeto y representarlo en un santiamén en nuestro cerebro.

Por eso permite que uno modifique instantáneamente el espectro sígnico representado.

La palabra, la lengua, de acuerdo con contextos y entonaciones es capaz de hacer que el corazón palpite más rápido, que la piel se nos vuelva miel, en fin, es

11 Claude Cadoz. Lesrélités virtudles Flammarion, París, 1990.

12 Cfr. Antulio Sánchez. "Comunicación y virtualidad", Topodilo México, núm. 44, enero-febrero, 1997. 
una vena de emociones. Pero, sobre todo, es un "instrumento" para imaginar, pensar y reflexionar. El ciberespacio se parece al lenguaje, emerge del mismo cerebro y, por consiguiente, resulta de la confección y del tratamiento elaborado de los signos. Por ello, en vez de preludiar una interacción y comunicación sin símbolos, la virtualidad es una clase distinta de intermediación con el entorno, tal vez el más horizontal en el mundo de la comunicación que conocemos.

Creo pues, para concluir, que veremos cada vez más cómo la nueva subjetividad descansará en signos virtuales, en signos que proceden de la fruición electrohumana 0 incluso totalmente electrónica. Esto, incluso, nos acorralará hasta en los acontecimientos cotidianos; hasta en las mismas calles o banquetas se multiplicará aún más el ciberespacio, demandándonos y saturándonos la visibilidad y nuestra presteza para digerirlos. Una hemorragia icónica en ascenso que no será el advenimiento de la catástrofe, pero tampoco será la varita mágica para escalar al cielo y solucionar los problemas que enfrenta la humanidad. Estamos todavía a tiempo para discutir lo que constituye el ciberespacio, para ponerlo al servicio de la vida, para que coadyuve en la nueva etapa del proceso civilizador en el que ya estamos inmersos, para entenderlo mejor y que no se torne en un lastre y factor de marginación para grandes colectivos de nuestro país y los del tercer mundo que carecen de estas cuestiones.

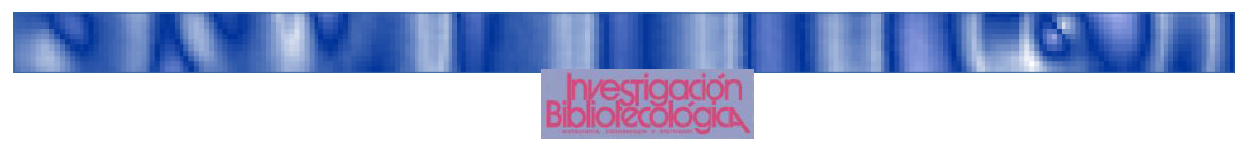

